Scottish Geographical Journal

\title{
Using Technology to Enhance Rural Resilience in Pre-Hospital Emergencies
}

\section{Anne Helen Schneider, Alasdair Mort, Peter Kindness, Chris Mellish, Ehud Reiter \& Phil Wilson}

To cite this article: Anne Helen Schneider, Alasdair Mort, Peter Kindness, Chris Mellish, Ehud Reiter \& Phil Wilson (2015) Using Technology to Enhance Rural Resilience in Pre-Hospital Emergencies, Scottish Geographical Journal, 131:3-4, 194-200, DOI: 10.1080/14702541.2014.978810

To link to this article: http://dx.doi.org/10.1080/14702541.2014.978810

$$
\begin{aligned}
& \text { (c) } 2015 \text { The Author(s). Published by Taylor \& } \\
& \text { Francis. }
\end{aligned}
$$

\section{曲 Published online: 26 Jan 2015.}

Submit your article to this journal ¿

\section{Џ Article views: 48}

\section{Q View related articles $\asymp$}

\section{View Crossmark data ¿}




\title{
Using Technology to Enhance Rural Resilience in Pre-Hospital Emergencies
}

\author{
ANNE HELEN SCHNEIDER ${ }^{\mathrm{a}, \mathrm{c}}$, ALASDAIR MORT $^{\mathrm{b}, \mathrm{c}}$, PETER KINDNESS $^{\mathrm{a}, \mathrm{c}}$, \\ CHRIS MELLISH $^{\mathrm{a}, \mathrm{c}}$, EHUD REITER $^{\mathrm{a}, \mathrm{c}} \&$ PHIL WILSON ${ }^{\mathrm{b}, \mathrm{c}}$ \\ ${ }^{a}$ Department of Computing Science, University of Aberdeen, King's College, Aberdeen, UK; ${ }^{b}$ Centre for Rural \\ Health, Inverness, UK; ${ }^{c}$ dot.rural the Digital Economy Hub at the University of Aberdeen, UK
}

(Received 8 April 2014; accepted 12 October 2014)

\begin{abstract}
This paper contributes to understanding of the geography of emergency pre-hospital care in rural Scotland and explores the role technology can play in improving the resilience of rural communities. In rural areas worldwide, it can be difficult to access appropriate health services locally and long journeys present challenges to the delivery of care. Poor mobile network coverage, remote locations with poor transport networks and inclement weather can all delay the arrival of help. The Scottish Ambulance Service operates a Community First Responder (CFR) scheme to care for patients in mainly rural areas while an ambulance is on its way. Community First Responders are volunteers trained in the basics of life-support but may have to care for patients with life-threatening illness (and sometimes injury) for a considerable period of time. Our paper showcases the Managing Information in Medical Emergencies project, which aims to support CFRs. We have developed novel technology to enable CFRs to capture a greater volume of patient data (including physiological parameters), provide them with an enhanced awareness of a patient's medical status and automatically generate handover reports for them. It is hoped that the handover reports improve the chain of communication from first person on scene to definitive care.
\end{abstract}

KEY WORDS: pre-hospital care, community resilience, demographic ageing, emergency medicine, first aid, community first responders, natural language generation

\section{Rural Medical Emergencies}

Responding to and managing medical emergencies in remote and rural areas with disperse populations is challenging. First, geography limits the speed at which emergency medical services can reach patients and then transport them to hospital; rural road networks are often poor and liable to disruption and even closure during winter. Island communities or peninsulas can also be cut off if a lifeline ferry service is cancelled because of poor tidal conditions or inclement weather. Second, there tend to be fewer health-care 'assets', including staff and vehicles. Staffing issues stem mainly from difficulties in recruiting and retaining appropriate rural health-care personnel (World Health Organization 2010).

Correspondence Address: Anne Helen Schneider, Department of Computing Science, University of Aberdeen, King's College, Aberdeen AB24 5UA, UK. Email: a.schneider@abdn.ac.uk

(C) 2015 The Author(s). Published by Taylor \& Francis.

This is an Open Access article distributed under the terms of the Creative Commons Attribution License (http:// creativecommons.org/licenses/by/4.0/), which permits unrestricted use, distribution, and reproduction in any medium, provided the original work is properly cited. 
There have also been changes to health-care service delivery in rural areas, with reducing numbers of local general practitioners and community nurses and novel models of care being introduced. Elsewhere, 'Fly in/Fly out' models have been proposed in rural Australia where doctors practice for a set number of days then return home on leave (Margolis 2012), as opposed to locating there on a permanent basis. These factors taken together make response to rural medical emergencies particularly fragile.

\section{Rural Patient Workload - A Distinct Sub-Type}

Rural health-care services tend to see a particular group of patients, which can be quite different from urban areas. For example, although the pattern of disease is similar between rural and urban areas, the overall number of accidents per head of population outnumbers those in urban areas and outcomes are worse (Remote and Rural Steering Group 2008). This includes a preponderance of patients arising from more extreme rural leisure pursuits, such as climbing (Mort \& Godden 2010; Mort \& Godden 2011) and diving, as well as those associated with occupational risk, for example, in agriculture and in the fishing industry. Sharp (2007) reported that 52\% of Scottish mountain rescue casualties are not Scottish residents; this tends to drive some seasonality in rural patient workload, with greater numbers treated in summer (e.g. hill walkers) and winter periods (e.g. snow sports). Furthermore, the incidence of alcohol-related disease (Remote \& Rural Steering Group 2008) and the suicide rate are higher in rural areas (Paykel et al. 2000).

Progressively more rural older adults will become recipients of emergency care, particularly if they suffer from one or more chronic conditions prone to periodic exacerbation. Demographic ageing, caused mainly by an increased life expectancy and a lower birth rate (Scottish Government Social Research 2010), is most pronounced in rural areas (Philip et al. 2012). There is also high out-migration of young people into urban areas in search of employment. For example, in 2007/2008 the out-migration of 16-24-year olds from rural to urban areas in Scotland was $6.1 \%$ (Scottish Government Social Research 2010). There is also in-migration of middle-aged groups who then 'age in place'. In several rural communities in Scotland (e.g. Dumfries and Galloway, Argyll and Bute and the Western Isles) the percentage of over 65-year olds exceeds $20 \%$. The shift in balance between young and old people is continuing, with a 50\% increase in the number of over 60-year olds projected by the year 2033 (Scottish Government Social Research 2010). The worsening dependency ratio (those aged $0-14$ and 65 years and over, divided by those aged 15-64 years) is very likely to increase the demands on limited-capacity local health and social-care services.

\section{Community Resilience and First Responder Schemes}

'Community Resilience' describes the effort of communities to facilitate their own healthcare by collective and collaborative response, using volunteers and informal carers and by promoting self-care (Remote and Rural Steering Group 2008). In order to improve community resilience in medical emergencies and maximise the chance of survival local Community First Responder (CFR) schemes have been introduced. According to the UK Resuscitation Council a CFR is a volunteer trained in 'basic life support and the use of a defibrillator, who attends a potentially life-threatening emergency'. ${ }^{1}$ Cardiac arrest is a good example of the type of emergencies CFRs are required to deal with, and illustrates 
the importance of their early intervention. The 'Chain of Survival' (Cummins et al. 1991) is a series of events that can help to improve the chance of survival following a heart attack. It has been shown that early cardiopulmonary resuscitation and defibrillation are crucial to maximise reduction in mortality (Eisenberg et al. 1979). With every minute that passes without treatment following a cardiac arrest, the patient's chances of survival decrease by $10 \%$ (Heward et al. 2004).

In Scotland over 1200, volunteers are currently organised in 137 CFR groups (personal communication with Scottish Ambulance Service, spring 2014 data) that are located mainly in rural and remote areas of Scotland where ambulance crews find it difficult or impossible to reach patients within the target response time of eight minutes. ${ }^{2}$ The greatest number of CFR schemes and CFRs is in the north of Scotland, which has the largest land area and lowest population density. It is their task to attend to the patient and record physiological measurements such as heart rate and breathing rate while they are awaiting the ambulance team. Upon the arrival of the ambulance they perform a handover, reporting back medical observations and actions taken, as well as the recorded physiological measurements of the patient. For this handover report the Scottish Ambulance Service introduced a paper patient report form. In practice, however, this paper form is seldom completed in-full on-scene (personal communication with CFRs) and (to avoid delay) a verbal handover is performed alone. This means that patient data are generally not captured contemporaneously, which could introduce error particularly in a time-pressured, stressful environment. Community First Responders have reported that they often feel helpless when managing patients, and mental and emotional demand is common (Kindness et al. 2014).

\section{Supporting Community Resilience Through the Mime Project}

The dotrural cross-disciplinary project 'Managing Information in Medical Emergencies' $(\mathrm{MIME})^{3}$ aims to improve the work routine for CFRs with respect to three main aspects (Schneider et al. 2014). One is to lift the burden from the CFR of regularly taking physiological measurements of the patient. In practice CFRs take the patient's heart rate and breathing rate manually. This happens intermittently at best and sometimes the measurements are written in ink on the back of a protective glove. In MIME we have developed a system that connects a tablet computer with novel lightweight medical sensors, which can be attached to the patient almost as soon as the CFR approaches. From the moment the sensors are attached they start recording the heart rate and blood oxygenation using a finger pulse oximeter, and breathing rate using an accelerometer device that is attached to the abdomen with medical tape. This ties in closely to the second aim of MIME which is to enhance the CFR's awareness of the patient's medical status and to provide some basic support messages. The tablet computer will display the patient's physiological measures and a traffic light system (a modified version of the National Early Warning System Score (Smith et al. 2013)) is used to make the CFR aware of patient deterioration or improvement. This can be especially relevant where there is a long wait for the arrival of the professional ambulance crew and if a patient's condition gradually deteriorates over time. Further, the tablet computer can be used to record other observations of the patient's condition (e.g. capillary refill) and actions that the CFR took (e.g. airway cleared) at the click of a single button. The third aspect of the MIME system is the generation of a handover report that can be relayed to the arriving ambulance crew on arrival. Managing Information in Medical 
Emergencies employs a natural language processing technique called Natural Language Generation (NLG) to transform the data streams of the sensors and the recorded observations and actions into a clear and concise textual handover report (Figure 1) that allows the ambulance crew to get a quick overview of the patient's condition and the medical measures that the CFR attempted. This also provides more information than would have been previously available through the continuous measurements of the patient's vital signs. In the NLG software, the input data from the CFR are combined with the incoming physiological data from the sensors and, since irrelevant information in the handover report can distract the recipient from data crucial to patient management, only relevant information is presented. For example, if the heart rate stays within the normal range throughout the incident, it is better to state this once in the report rather than continually reporting the heart rate.

HANDOVER REPORT

TIME OF STARTUP: $10: 31: 00$

TIME OF HANDOVER: 10:43:00

CASUALTY

Casualty is 54 year old, male.

INCIDENT DETAILS

Man is experiencing severe chest pain in his rural home. His wife calls 999 at 10:23 as she thinks her husband is having a heart attack - he has experienced angina periodically for around five years

\section{INITIAL ASSESSMENT}

On examination the casualty's airway was open, his skin was pale, his capillary refill was slow and he had pain in his chest. His pulse rate was 100 beats per minute, he was breathing at 18 breaths per minute and his blood oxygen saturation was $92 \%$.

\section{TREATMENT AND FINDINGS}

At 10:32 high flow oxygen was applied and he took his GTN spray. Then Sp02 rapidly increased to $96 \%$. However, after that Sp02 remained constant around $95 \%$ for 10 minutes.

At 10:35 he was feeling faint.

At 10:35 the casualty was moved.

At 10:38 he had pain in his chest.

At 10:38 he was vomiting.

After treatment HR has remained fairly constant around $109 \mathrm{bpm}$ for 11 minutes, RR has remained constant around $22 \mathrm{bpm}$ for 2 minutes and $\mathrm{SpO} 2$ has remained constant around $95 \%$ for 10 minutes.

MEDICATION, ALLERGIES AND PAST MEDICAL HISTORY

Figure 1. Example of a handover report generated by the MIME system. 
Evaluation of a system like MIME encounters a number of practical and ethical challenges. Currently, five inter-related evaluation tasks are underway with the second MIME prototype (Figure 2). One evaluation strand tests the sensors and tablet software in real emergency conditions. In a field study, a member of the research team has been attending call outs with a Scottish ambulance station (they attend call outs as an observer and do not interfere with or influence medical interventions) testing the second prototype of the MIME system and the sensor functionality. With the collected data we can test the MIME system's handover report generator and analyse the influence of 'noise' in the sensor data that can occur as a result of inaccuracies in hardware measurements or as artefacts during the transmission of the data; such distortion of typically rhythmic and stable signal patterns is common during motion and often results in false alarms (Wikilund et al. 1994; Sinex 1999).

The second vital aspect of the MIME system is its usability. A requirement of the interface is that it needs to be simple and intuitive to use and should at all times avoid overloading the CFR with what is termed 'creeping featurism' (His \& Potts 2000) or 'bloated' software (McGrenere et al. 2002). Hence the interface design and also the decision procedure around the hardware are undergoing an iterative development process of requirement analysis, user testing and refinement (Schneider et al. 2013a).

Third, it is vital that the generated handover reports provide a quick overview of the situation but at the same time are comprehensive. The format must be readable and irrelevant

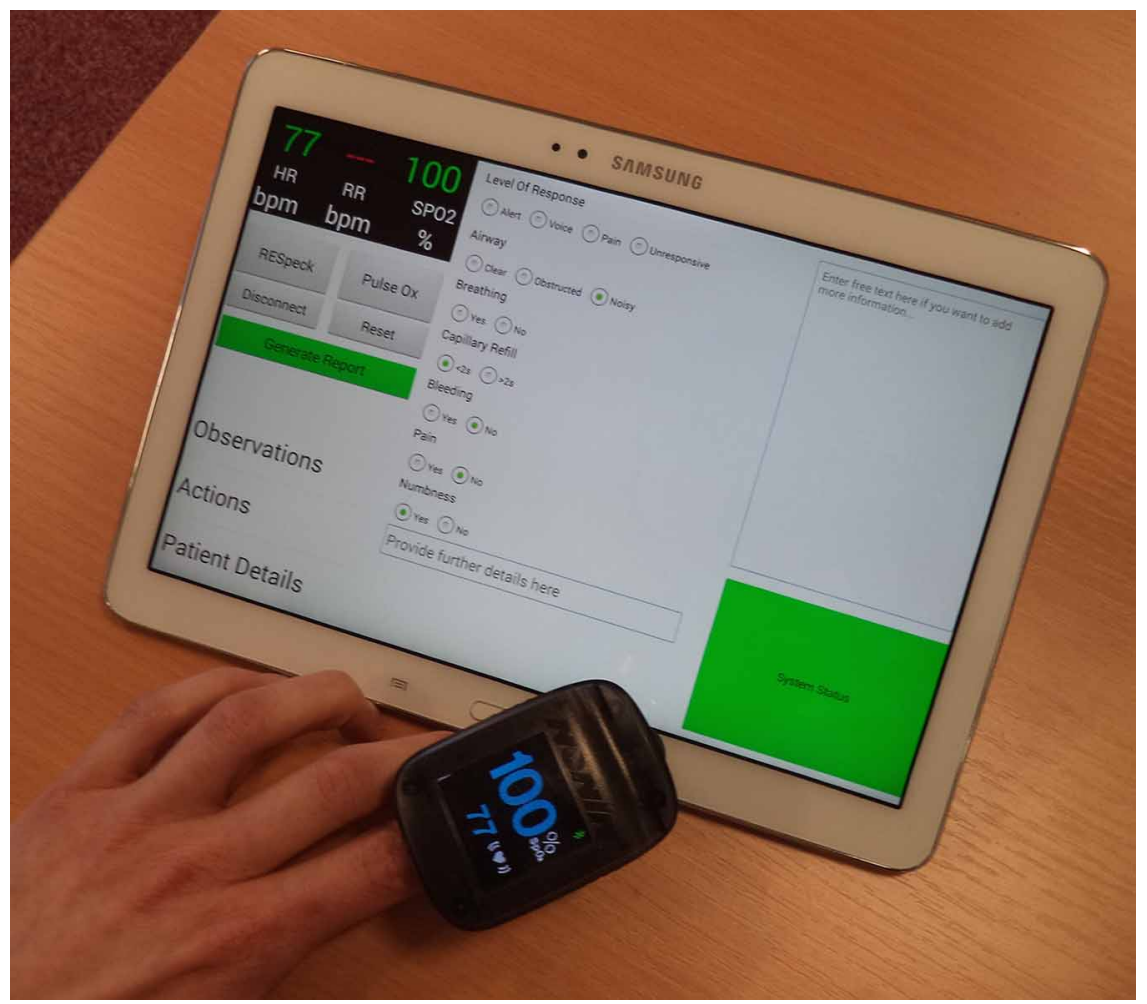

Figure 2. Second hardware prototype of the MIME system. 
material needs to be suppressed in order not to overload the ambulance clinicians and hinder interpretation. Hence, the NLG component of the system is undergoing a rigorous evaluation process, which is carried out in several stages (Schneider et al. 2013b).

The MIME system also presents the opportunity to support the well-being of the care providers as well as the care receivers through targeted support messages (Kindness et al. 2013). The application of tailored emotional support messages, constructed by utilising emotional support categorisations, such as praise, reassurance and emotional reflection, provides the opportunity to consider and support the emotions experienced by users who voluntarily enter situations where stress is inherent. Finally, we plan to carry out laboratory-based studies where CFRs use the MIME system with a simulated casualty, in order, as far as possible, to determine how it would be used in real situations.

\title{
5. Conclusion
}

Community First Responders are now an integral part of community resilience in rural Scotland and further afield. However, due to a number of factors, the task of providing healthcare in rural emergency situations is extremely challenging and CFRs are in general relatively inexperienced. Volunteer First Responder Schemes can experience the problem of a high dropout rate, potentially as a result of stress (Rørtveit \& Meland 2010). This problem is addressed in part by the MIME project, which aims to support the task of CFRs by enabling them to capture a greater volume of physiological patient data as well as giving them a better awareness of a patient's medical status so they can deliver more effective care. We aim to improve the process of handover between CFR and arriving ambulance crew using Natural Language Generation to generate handover reports. By improving the CFRs' task the MIME project can contribute to community resilience, enabling rural communities to sustain a more effective and efficient response in emergencies.

\section{Funding}

The research presented in this paper is supported by RCUK dot.rural Digital Economy Research Hub, University of Aberdeen [grant number EP/G066051/1].

\author{
Notes \\ ${ }^{1}$ https://www.resus.org.uk/pages/FirstRsp.htm (last accessed 25/07/2014). \\ 2 http://www.scottishambulance.com/ (last accessed 25/07/2014). \\ 3 http://www.dotrural.ac.uk/mime/ (last accessed 25/07/2014).
}

\section{References}

Cummins, R. O., Ornato, J. P. Thies, W. H. \& Pepe, P. E. (1991) Improving survival from sudden cardiac arrest: the "chain of survival" concept. Advanced Cardiac Life support subcommittee and the emergency cardiac care committee, American heart association, Circulation, vol. 83, no. 5, pp. 1832-1847.

Eisenberg, M., Bergner, L. \& Hallstrom, A. (1979) Paramedic programs and out-of-hospital cardiac arrest: I. Factors associated with successful resuscitation, American Journal of Public Health, vol. 69, no. 1, pp. 30-38.

Heward, A., Damiani, M. \& Hartley-Sharpe, C. (2004) Does the use of the advanced medical priority dispatch system affect cardiac arrest detection? Emergency Medicine Journal, vol. 21, no. 1, pp. 115-118. 
His, I. \& Potts, C. (2000) 'Studying the evolution and enhancement of software features'. Proceedings of the International Conference on Software Maintenance, ICSM '00, Washington, DC, pp. 143-151.

Kindness, P., Dennis, M. Mellish, C. Masthoff, J. \& Smith, K. (2013) Towards Affective Emotional Support for Community First Responders Experiencing Stress. AFFINE workshop, Affective Computing and Intelligent Interaction, Geneva.

Kindness, P., Fitzpatrick, D. Mellish, C. Masthoff, J. O’Meara, P. \& McEwan, M. (2014) The need to address stress: an insight into the demands and stressors experienced by first responders, Journal of Paramedic Practice, vol. 6, no. 7, pp. 362-369.

Margolis, S.A. (2012) Is fly in/fly out (FIFO) a viable interim solution to address remote medical workforce shortages? Rural Remote Health, vol. 12, article 2261. [Online] Available at: http://www.ncbi.nlm.nih.gov/ pubmed/23046214

McGrenere, J., Baecker, R. M. \& Booth, K. S. (2002) 'An evaluation of a multiple interface design solution for bloated software'. Proceedings of the SIGCHI Conference on Human Factors in Computing Systems. April 2002; Minneapolis, Minnesota, [Online] Available at: http://portal.acm.org/citation.cfm?id=503406

Mort, A. J. \& Godden, D. J. (2010) UK mountain rescue casualties: 2002-2006, Emergency Medicine Journal, vol. 27, no. 4, pp. 309-312.

Mort, A. J. \& Godden, D. J. (2011) Injuries to individuals participating in mountain and wilderness sports, Clinical Journal of Sports Medicine, vol. 21, no. 6, pp. 530-536.

Paykel, E., Abbott, R., Jenkins, R., Brugha, T. \& Meltzer, H. (2000) Urban-rural mental health differences in Great Britain: findings from the national morbidity survey, Psychological Medicine, vol. 30, no. 2, pp. 269-280.

Philip, L. J., Brown, D. \& Stockdale, A. (2012) Demographic ageing in rural areas: insights from the UK and US, in: M. Shucksmith, D. Brown, M. Warner, J. Vergunst \& S. Shortall (eds) Rural Transformations and Policies in the UK and US, pp. 58-78 (New York: Routledge).

Remote and Rural Steering Group. (2008) Delivering for Remote and Rural Healthcare - The Final Report of the Remote and Rural Workstream, [Online] Available at: http://www.scotland.gov.uk/Resource/Doc/222087/ 0059735.pdf

Rørtveit, S. \& Meland, E. (2010) First responder resuscitation teams in a rural Norwegian community: sustainability and self-reports of meaningfulness, stress and mastering, Scandinavian Journal of Trauma, Resuscitation and Emergency Medicine, vol. 18, no. 1, article 25. [Online] Available at: http://www.ncbi.nlm.nih.gov/pmc/ articles/PMC2879234/

Schneider, A. H., Mort, A. Mellish, C. Reiter, E. \& Wilson, P. (2014) 'Targeting challenges in rural emergency care', Proceedings of 3rd EURUFU conference 'Social and Healthcare Issues in Rural Areas'. Sondershausen, pp. 44-51.

Schneider, A. H., Sharma, N. Mort, A. J. Mellish, C. S. Reiter, E. B. \& Wilson, P. (2013a) 'Designing a mobile device for pre-hospital care', Paper presented at 7th Annual Irish HCI Conference 2013 (iHCI'13), Dundalk, Ireland.

Schneider, A. H., Vaudry, P. L. Mort, A. J. Mellish, C. S. Reiter, E. B. \& Wilson, P. (2013b) 'MIME - NLG in pre-hospital care', Proceedings of the 14th European Workshop on Natural Language Generation (ENLG'13), Sofia, Bulgaria, Stroudsberg, PA, Association for Computational Linguistics, pp. 152-156.

Scottish Government Social Research. (2010) Demographic Change in Scotland, [Online] Available at: http:// www.scotland.gov.uk/Resource/Doc/332379/0108163.pdf

Sharp, B. (2007) Scottish Mountaineering Incidents (1996-2005). Sportscotland research report 109, Edinburgh, Sportscotland.

Sinex, J. E. (1999) Pulse oximetry: principles and limitations, The American Journal of Emergency Medicine, vol. 17, no. 1, pp. 59-66.

Smith, G. B., Prytherch, D. R. Meredith, P. Schmidt, P. E. \& Featherstone, P. I. (2013) The ability of the national early warning score (NEWS) to discriminate patients at risk of early cardiac arrest, unanticipated intensive care unit admission, and death, Resuscitation, vol. 84, no. 4, pp. 465-470.

Wikilund, L., Hök, B. Stähl, K. \& Jordeby-Jönsson, A. (1994) Postanesthesia monitoring revisited: frequency of True and false Alarms from different monitoring devices, Journal of Clinical Anaesthesia, vol. 6, no. 3, pp. 182188.

World Health Organization. (2010) Increasing Access to Health Workers in Remote and Rural Areas Through Improved Retention: Global Policy Recommendations (Geneva: World Health Organization) 